\title{
Genetic and Physical Maps of Klebsiella aerogenes Genes for Histidine Utilization (hut)
}

\author{
S.A. Boylan and R.A. Bender \\ Department of Cellular and Molecular Biology, Division of Biological Sciences, University of Michigan, Ann Arbor, MI 48109, USA
}

Summary. Deletion derivatives of the hut-containing plasmid pCB101 were tested against point mutants defective in individual genes of the histidine utilization (hut) operons using a complementation/recombination assay. Location of the genes of the right operon, hut $U$ and hut $H$, was confirmed by direct assay of the gene products, urocanase and histidase; location of the repressor gene was identified by measuring the ability of the plasmid-carried genes to repress the formation of histidase from a chromosomal location. The analysis of eight deletion plasmids unambiguously con-

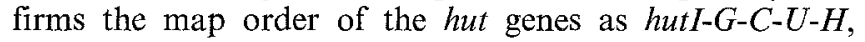
and demonstrates that, in Klebsiella aerogenes, the hutU and $h u t H$ genes are transcribed from their own promoter. In addition, the genetic map of hut can be aligned with the restriction map of the hut DNA in plasmid pCB101. One of the deletion plasmids studied apparently encodes a defective histidase subunit that is trans-dominant to active histidase. Another deletion, which completely removes the left operon, hutIG, allows high level expression of the hutUH operon and thus overproduction of a toxic intermediate.

\section{Introduction}

The amino acid histidine can be degraded by Klebsiella aerogenes in a sequence of four enzymatic reactions (reviewed by Magasanik 1978). Histidine is first deaminated by histidase (the product of the hutH gene) to urocanic acid, the physiological inducer of the entire degradative system. Urocanase (encoded by hut $U$ ) then converts urocanic acid to imidazolone propionate, a toxic intermediate. Imidazolone propionate hydrolase (encoded by huth) then cleaves the ring to yield formimino glutamic acid, which is further cleaved by formiminoglutamate hydrolase (encoded by $h u t G$ ) to give glutamic acid, a potentially useable carbon and nitrogen source, and formamide, which is excreted. The histidine utilization (hut) genes are clustered on the K. aerogenes chromosome in a region between gal and bio (Goldberg and Magasanik 1975). The hut genes are absent from Escherichia coli but are found in the gal-bio region in Salmonella typhimurium where they are arranged as two adjacent operons.

The hut operons of $K$. aerogenes provide an attractive model system to study regulation of gene expression in bac-

Offprint requests to: R.A. Bender teria (Magasanik 1978). Expression of hut genes is controlled at many levels. (1) The hutC gene product is a regulated repressor whose natural inducer, urocanate, is produced by the first enzyme of the pathway, histidase, and is destroyed by the second enzyme, urocanase, (Schlesinger et al. 1965; Prival and Magasanik 1971) (2) hut expression requires a positive activator, either $\mathrm{CAP}+\mathrm{cAMP}$ in response to carbon limited growth, or an unknown factor(s) in response to nitrogen-limited growth (Neidhardt and Magasanik 1957; Prival and Magasanik 1971), and (3) hut expression further requires the presence of an exogenous electron acceptor (Goldberg and Hanau 1980). All these effects are at the transcriptional level and their targets seem to lie in the operator-promoter regions.

In the preceding paper (Boylan et al. 1983), we described the restriction endonuclease cleavage map of the hut region from $K$. aerogenes and the isolation of a set of deletions removing various segments of this DNA. In the present paper, we use these deletions to determine the map order of the structural genes, confirming the order deduced from transductional analysis (Goldberg and Magasanik 1975). We also show that the $K$. aerogenes hut cluster, like that in S. typhimurium, is transcribed in the direction from hutI to hut $H$, and is arranged into at least two independent transcription units with hutUH expressed even in the absence of the entire hutIG operon. The results presented here and in the accompanying paper (Boylan et al. 1983) allow us to identify the location of hutP, the promoter region of the hutUH operon, for our studies of regulated in vitro transcription using components purified from $K$. aerogenes.

\section{Materials and Methods}

Bacteria and Growth Media. The strains used in this study are listed in Table 1. Minimal medium contained W salts (Prival and Magasanik 1971), carbon sources at $0.4 \%$, and nitrogen sources at $0.2 \%$. When histidine or urocanate was sole carbon and nitrogen source, it was added to $0.4 \%$. A solution of glutamine (Calbiochem grade A) was freshly prepared before addition to medium. Inducer (histidine or urocanate) was present at $0.2 \%$. Plasmid-containing strains were grown in the presence of ampicillin at $25 \mu \mathrm{g} / \mathrm{ml}$ (E. coli) or $500 \mu \mathrm{g} / \mathrm{ml}$ (K. aerogenes).

Transformations. Competent cells were prepared and transformed with plasmid DNA as described by Lederberg and Cohen (1974) and transformants were selected on LB plates 
Table 1. Bacterial strains employed

\begin{tabular}{|c|c|c|}
\hline Strain & Genotype & Origin \\
\hline \multicolumn{3}{|c|}{ Escherichia coli } \\
\hline EB649 & $\begin{array}{l}\text { hsr, lac, gal, rpsL594 } \\
\text { (pBR322) }\end{array}$ & $\begin{array}{l}\text { transformation } \\
\text { of EG47 }\end{array}$ \\
\hline EB841 & $\begin{array}{l}\text { hss-1, thi-1, lacY1, tonA21, } \\
\text { supE44 (pCB106) }\end{array}$ & $\begin{array}{l}\text { transformation } \\
\text { of } \mathrm{RH} 202\end{array}$ \\
\hline EB890 & $\begin{array}{l}\text { hss-1, thi-1, lacY1, tonA21, } \\
\text { supE44 (pCB102) }\end{array}$ & $\begin{array}{l}\text { transformation } \\
\text { of } \mathrm{RH} 202\end{array}$ \\
\hline EB896 & $\begin{array}{l}\text { hss-1, thi-1, lacY1, tonA21, } \\
\text { supE44, (pCB101) }\end{array}$ & $\begin{array}{l}\text { transformation } \\
\text { of } \mathrm{RH} 202\end{array}$ \\
\hline EG47 & hsr lac gal rpsL594 & $\begin{array}{l}\text { (Goldberg et al. } \\
\text { 1974) }\end{array}$ \\
\hline $\mathrm{RH} 202$ & $\begin{array}{l}\text { hss-1, thi-1, lac Y1, tonA21, } \\
\text { supE44 }\end{array}$ & $\begin{array}{l}\text { (Adams et al. } \\
\text { 1979) }\end{array}$ \\
\hline \multicolumn{3}{|c|}{ Klebsiella aerogenes } \\
\hline KB897 & hutC516, hutI519, (pCB102) & $\begin{array}{l}\text { transformation } \\
\text { of KG2005 }\end{array}$ \\
\hline KB899 & hutC516, hut1519, (pCB113) & $\begin{array}{l}\text { transformation } \\
\text { of } \mathrm{KG} 2005\end{array}$ \\
\hline KB936 & hutC516, hut1519, (pCB101) & $\begin{array}{l}\text { transformation } \\
\text { of } \mathrm{KG} 2005\end{array}$ \\
\hline KB937 & hutC516, hutI519, (pCB103) & $\begin{array}{l}\text { transformation } \\
\text { of } K G 2005\end{array}$ \\
\hline KB965 & hutC516, hut1519, (pBR322) & $\begin{array}{l}\text { transformation } \\
\text { of KG2005 }\end{array}$ \\
\hline $\mathrm{KG} 2000$ & $h u t^{+}$ & $\begin{array}{l}\text { (Goldberg and } \\
\text { Magasanik 1975) }\end{array}$ \\
\hline $\mathrm{KG} 2003$ & hutC516, hutH518 & $\begin{array}{l}\text { (Goldberg and } \\
\text { Magasanik 1975) }\end{array}$ \\
\hline $\mathrm{KG} 2005$ & hutC516, hutI519 & $\begin{array}{l}\text { (Goldberg and } \\
\text { Magasanik 1975) }\end{array}$ \\
\hline KG2007 & hutC517, hutU520 & $\begin{array}{l}\text { (Goldberg and } \\
\text { Magasanik 1975) }\end{array}$ \\
\hline $\mathrm{KG} 2010$ & hutG504 & $\begin{array}{l}\text { (Goldberg and } \\
\text { Magasanik 1975) }\end{array}$ \\
\hline
\end{tabular}

supplemented with ampicillin. Transformation of $K$. aerogenes has not been described previously and the frequency of transformants seen with $K$. aerogenes strain was quite similar to that seen with $E$. coli. To test for complementation/recombination, five colonies from the LB ampicillin selection plate were picked with sterile toothpicks and patched onto minimal medium plates with histidine or urocanate as sole carbon source. A solid patch for each of the colonies indicated complementation, growth of 5-35 colonies in each of the five patches indicated recombination; no growth whatsoever in each of the five patches indicated neither complementation nor recombination. No other phenotype was seen.

Enzyme Assays. Histidase and urocanase were assayed as described by Brill and Magasanik (1969) except that whole, undisrupted cells were used and CTAB (hexadecyltrimethylammonium bromide) was added to the reaction mixtures at $100 \mu \mathrm{g} / \mathrm{ml}$ to render the cells permeable (Bender et al. 1977). One unit of activity is the amount of enzyme required to produce $1 \mathrm{nmol}$ of product or degrade $1 \mathrm{nmol}$ of substrate per min at $37^{\circ} \mathrm{C}$. Whole cells were assayed for protein
Table 2. Complementation of hut deletion plasmids

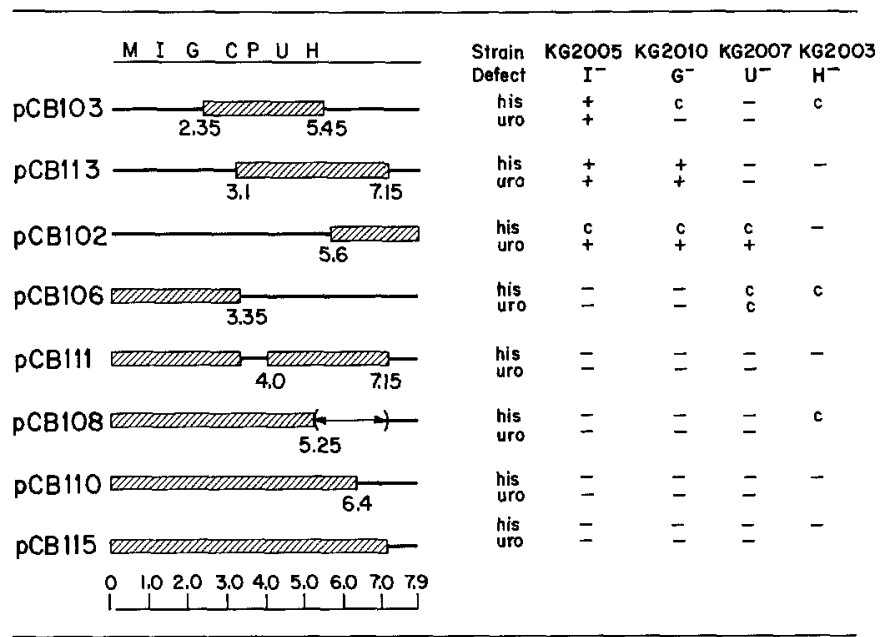

Deletions are indicated by a cross-hatch and are placed with respect to the HindIII sites of the cloned hut DNA. Only the $K$. aerogenes DNA from the plasmids is shown here. Klebsiella aerogenes strains KG2005 (huth), KG2010 (hutG), KG2007 (hutU) and KG2003 (hutH) were transformed according to the procedure described in Materials and Methods. Transformant colonies appearing on LB plates supplemented with ampicillin were patched directly onto both histidine and urocanate minimal media plates and scored for growth after $26 \mathrm{~h}$ at $37^{\circ} \mathrm{C}$. Strain KG2003 does not require any additional genes for growth on urocanate so the growth on urocanate is not reported for this strain. $+=$ solid growth in streak, indicating complementation, $-=$ no growth in streak, $\mathrm{C}=5-35$ colonies in streak area indicating recombinations

by the method of Lowry et al. (1951) using crystaline bovine serum albumin (Sigma) as standard

\section{Results}

Complementation of hut Mutants with hut Deletion Plasmids

Plasmid pCB101 is a derivative of pBR322 carrying the hut genes of $K$. aerogenes. Plasmids deleted for varying amounts of hut DNA (Boylan et al. 1983) were used to transform $K$. aerogenes strains defective in one of the four hut structural genes (Goldberg and Magasanik 1975), and the transformants were tested for the ability to utilize histidine or urocanate as sole carbon source (Table 2).

Plasmid pCB103 allowed the hutI strain KG2005 to grow as a solid patch on plates containing either histidine or urocanate as sole carbon and nitrogen source, demonstrating that pCB103 complements the hutI mutation. No such complementation was seen when pCB103 was tested in either a hutG or hutH strain, but several colonies grew in the streaked area indicating that recombination had occurred. Thus pCB103 carries an active hut $I^{+}$gene and at least part of the hutG and hutH genes. The failure of pCB103 to show either complementation or recombination in a hut $U$ strain showed that at least the portion of the $h u t U$ gene identified by the hut $U$ allele used here is removed by the deletion in pCB103. Plasmid pCB113, whose deletion maps further to the right of that in pCB103, complemented not only the hutI mutation, but also the hutG. However, it could neither complement nor recombine with the hutII mutation to provide a hut $H^{+}$gene (Table 2). Therefore the hutIG region occupies the left end of the cloned hut fragment as depicted in Table 2. This orientation is confirmed 
by the complementation data for plasmid pCB102. The mutations in hutI, hutG, and hutU are complemented for growth of the transformant on urocanate by pCB102 (Table 2). The failure of pCB102 to complement these same mutations for growth on histidine will be discussed later. The hut $H$ transformant did not grow at all on histidine plates nor did it yield colonies in the patch, indicating that the pCB102 deletion removes the region of hut $H$ defined by the hutH518 allele. Plasmid pCB110 whose deletion enters the hut $H$ region from the left, was also unable to give $h u t H^{+}$recombinants with the hutH518 allele. Thus the hutH518 mutation must lie between map positions 5.6 and 6.4 , the region missing from both the deletion in pCB102 and that in pCB110. Other plasmids which contain this region, even in an inverted orientation (see pCB108), did recombine with hutH518.

\section{Plasmid pCB102 Encodes a Trans-dominant Negative Histidase}

As noted above, pCB102 fails to complement hutI, hutG, or hut $U$ mutants for growth on histidine despite the presence of active hutI, hutG, and hut $U$ genes on the plasmid (Table 2). The presence of an active hut $U$ gene was confirmed by direct assay for urocanase in strain EB890, an E. coli strain carrying pCB102. Urocanase expression was indistinguishable both in quantity and in inducibility from that in strain EB896 carrying a complete hut operon on pCB101. Furthermore, no histidase was produced from pCB102, in agreement with the complementation data showing the absence of an active hut $H$ gene. A similar analysis of $K$. aerogenes strain KB897 carrying a wild type hut operon on the chromosome as well as pCB102 again suggested that urocanase was synthesized from the pCB102 gene and that this synthesis was induced by urocanate. Urocanase synthesis in KB897 was not induced by histidine, however, perhaps reflecting the increased gene dosage for the inducer-degrading enzyme, urocanase, relative to the inducer-forming enzyme, histidase.

Since pCB102 does not provide an active hut H gene, the histidase formed in strain KB897 must have been chromosomally encoded. Nevertheless, plasmid pCB102 interfered with the normal regulation of this chromosomally encoded hut $H$ product. Whereas urocanase showed the normal ten-fold induction by urocanate, histidase levels rose less than three-fold upon induction (Table 3). Furthermore, the maximal histidase level seen in the presence of pCB102 was only $20 \%$ of that seen in the absence of pCB102 (strains KB897 and KB965). Thus, induction of the hut UH operon on pCB102 blocked the expression of induced levels of histidase for the chromosomal hut $H$ gene in trans, recalling the trans-dominant hutH mutation described previously (Hagan et al. 1974).

\section{Histidine Toxicity and $p C B 106$}

Strains carrying pCB106 express high levels of hut $U$ and hutH product (Table 3, line 4), yet pCB106 does not complement hutU or hutH mutations (Table 2). Even hut ${ }^{+}$ strains transformed with pCB106 are severely defective for growth on histidine as sole carbon source (not shown). The product of the hut $U$ gene product, 4-imidazolone-5-propionate (IP), is toxic to $K$. aerogenes unless further metabolized by the enzymes encoded by hut I and hutG (Schlesinger and Magasanik 1965). Since pCB106 lacks hutI and hutG genes
Table 3. Regulation of histidase and urocanase formation in plasmid-bearing strains

\begin{tabular}{|c|c|c|c|c|}
\hline \multirow[t]{2}{*}{ Strain } & \multirow[t]{2}{*}{ Plasmid } & \multirow[t]{2}{*}{ Inducer } & \multicolumn{2}{|c|}{ Specific activity $(\mu / \mathrm{mg})$} \\
\hline & & & Histidase $^{\mathrm{a}}$ & Urocanase \\
\hline EB649 & pBR322 & $\begin{array}{l}\text { none } \\
\text { uro }\end{array}$ & $\begin{array}{l}\leqq 1.0 \\
\leqq 1.0\end{array}$ & $\begin{array}{l}\leqq 0.3 \\
\leqq 0.3\end{array}$ \\
\hline EB896 & pCB101 & $\begin{array}{l}\text { none } \\
\text { uro }\end{array}$ & $\begin{array}{l}17.6 \\
52\end{array}$ & $\begin{array}{l}1.3 \\
4.3\end{array}$ \\
\hline EB890 & pCB102 & $\begin{array}{l}\text { none } \\
\text { uro }\end{array}$ & $\begin{array}{l}\leqq 1.0 \\
\leqq 1.0\end{array}$ & $\begin{array}{l}1.1 \\
6.0\end{array}$ \\
\hline EB841 & pCB106 & $\begin{array}{l}\text { none } \\
\text { uro }\end{array}$ & $\begin{array}{l}182 \\
125\end{array}$ & $\begin{array}{l}14.4 \\
12.4\end{array}$ \\
\hline $\mathrm{KG} 2000$ & none & $\begin{array}{l}\text { none } \\
\text { his } \\
\text { uro }\end{array}$ & $\begin{array}{r}4.3 \\
52.8 \\
45.1\end{array}$ & $\begin{array}{l}0.61 \\
5.6 \\
5.4\end{array}$ \\
\hline KB965 & pBR322 & $\begin{array}{l}\text { none } \\
\text { his } \\
\text { uro }\end{array}$ & $\begin{array}{l}47.3 \\
53 \\
56.4\end{array}$ & $\begin{array}{l}4 \\
6.1 \\
5.6\end{array}$ \\
\hline KB936 & pCB101 & $\begin{array}{l}\text { none } \\
\text { his } \\
\text { uro }\end{array}$ & $\begin{array}{l}17.9 \\
172 \\
117\end{array}$ & $\begin{array}{r}1.5 \\
14.8 \\
10.6\end{array}$ \\
\hline KB937 & pCB103 & $\begin{array}{l}\text { none } \\
\text { his } \\
\text { uro }\end{array}$ & $\begin{array}{l}52.4 \\
48.7 \\
46\end{array}$ & $\begin{array}{l}\mathrm{ND}^{\mathrm{b}} \\
\mathrm{ND} \\
\mathrm{ND}\end{array}$ \\
\hline KB899 & pCB113 & $\begin{array}{l}\text { none } \\
\text { his } \\
\text { uro }\end{array}$ & $\begin{array}{l}43.5 \\
51.6 \\
44.2\end{array}$ & $\begin{array}{l}\mathrm{ND} \\
\mathrm{ND} \\
\mathrm{ND}\end{array}$ \\
\hline KB897 & pCB102 & $\begin{array}{l}\text { none } \\
\text { his } \\
\text { uro }\end{array}$ & $\begin{array}{l}3.75 \\
5.1 \\
9.4\end{array}$ & $\begin{array}{l}1 \\
1.1 \\
9.4\end{array}$ \\
\hline
\end{tabular}

Cultures were grown and enzyme assays were carried out as in Methods Growth medium consisted of $0.4 \%$ glucose and $0.2 \%$ ammonium sulfate in minimal salts. Strain KG2000 has an active repressor gene $\left(\right.$ hutC $^{+}$) expressed from the chromosome; all other $K$. aerogenes strains carry the hutC516 allele on the chromosome abolishing production of active repressor from the chromosome. $E$. coli strains lack hut genes (including repressor). All $K$. aerogenes strains designations begin with $\mathrm{K}$ while $E$. coli designations begin with $\mathrm{E}$

a Inducers were His (0.2\% histidine) urocanate (Uro) $(0.2 \%$ urocanate)

b Not determined

to balance the high number of copies of hutH and hutU, transformants with pCB106 might accumulate high levels of IP when provided with histidine or urocanate. This could explain why even a hut ${ }^{+}$strain grew poorly on histidine or urocanate as sole carbon source when carrying pCB106. When an E. coli strain transformed with pCB106 (EB841) was grown in a derepressing medium and transferred from histidine-free to histidine-supplemented medium, the cells died rapidly (Fig. 1). In contrast, E. coli strain EB649 containing only pBR322 grew very slowly with histidine as sole nitrogen source (probably via transaminations) while strain EB896 containing pCB101 (with a complete hut gene cluster) grew well (Fig. 1).

\section{Location of the Repressor Gene (hutC)}

Both pCB102 and pCB106 promoted urocanase synthesis in E. coli. The expression of urocanase from pCB102 re- 


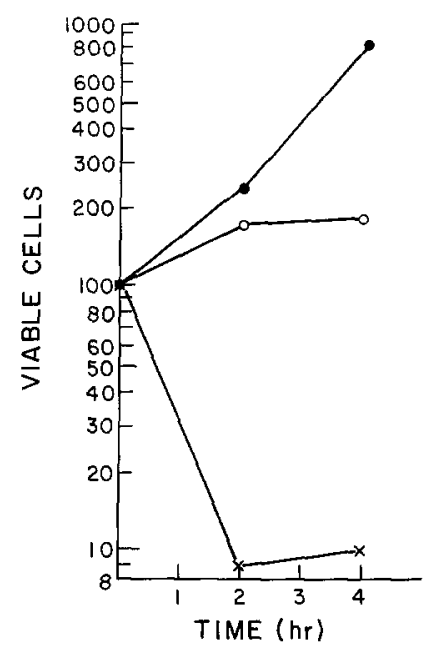

Fig. 1. The effects of histidine on the viability of a pCB106 transformant. Strains were grown overnight at $30^{\circ} \mathrm{C}$ in a medium containing $0.4 \%$ glucose, $0.2 \%$ glutamine and $0.2 \%$ urocanate. The next morning, cultures were diluted with fresh medium and their growth was followed by Klett units and viable counts. The growing cultures were then washed twice with $\mathrm{W}$ salts (See Materials and Methods) and brought to a Klett value of 10 in a $0.4 \%$ glucose and $0.4 \%$ histidine medium. Five $\mathrm{ml}$ cultures were grown at $37^{\circ} \mathrm{C}$ in $125 \mathrm{ml}$ Klett flasks. Viable counts were determined by diluting a sample of the culture and plating on LB amp plates. The value at $t=0$ was set at 100 and subsequent titres are expressed relative to this value. o, strain EB649, which carries pBR322; $\bullet$ strain EB896, which carries pCB101; $\times$, strain EB841, which carries pCB106

quired inducer, whereas that from pCB106 did not (Table 3, strains EB890 and EB841). Thus the repressor gene (hutC) was expressed from pCB102 but not from pCB106. The location of the hutC gene was further delimited by testing the ability of two plasmids that do not express $h u t H$ to repress hutH expression from a chromosomal hut which lacks an active hutC product of its own. Neither pCB103 nor pCB113 provided active repressor for the regulation of chromosomally encoded histidase or urocanase expression (Table 3, strains KB937 and KB899). Thus hutC lies at least partially to the right of the endpoint of the deletion in pCB113 (at position 3.15) and at least partially to the left of the endpoint of the deletion in pCB106 (at position 3.35 ).

\section{Discussion}

The data presented here yield an unambiguous map order of the hut genes based on deletions, confirming the order deduced from transductional analysis. The deletion plasmid pCB103 carries hutI and at least part of hutG and hutH since pCB103 recombines with hut $G$ and hut $H$ mutations and complements a hutI mutation. Plasmid pCB113 carries DNA corresponding to the left end of the deletion in pCB103 and expresses hutG but not hutC, hutU or hutH activity in complementation tests, establishing the order hutI, hutG, (hutCUH). Plasmid pCB102, whose deletion enters $h u t$ from the right, expresses all the hut genes except $h u t H$. Thus the hutH gene is rightmost and the order is hutI, hutG, (hutCU), hutH. Finally, plasmid pCB106, whose deletion enters $h u t$ from the left, lacks $h u t I, h u t G$, and $h u t C$ activities, but expresses both hutU and hutH. Therefore $h u t C$ is to the left of hut $U$ and the final map order must be hutI, hutG, hutC, hutU, hutH.

Since the deletions used in this study were derived from restriction endonuclease digests, we can align the genetic map deduced above with the restriction map presented in the accompanying paper (Boylan et al. 1983). For example, the hutG extends rightward beyond the BglII site at map position 2.35 but ends before the $K p n I$ site at 3.1 since the $B g / I I-g e n e r a t e d$ deletion in pCB103 abolished hutG expression but the KpnI-generated deletion in pCB113 did not. Similarly, at least part of hutC must lie to the right of 3.1 since the KpnI-generated deletion in pCB113 abolished hutC expression. Since hut $U$ and hut $H$ are expressed at normal levels from pCB106, the promoter region of the hutUH operon, here called hutP, must lie to the right of the Sall site at map position 3.35 .

The data in Table 3 show clearly that the deletion in pCB102 interrupts the hut $H$ gene, but the ability of pCB102 expression to interfere with chromosomal hut $H$-encoded histidase activity strongly resembles the trans-dominant hut $H$ mutation described by Hagen et al. (1974). This would predict that a portion of hutH remains and that the polypeptide produced by this fusion of hut $H$ sequences with "foreign" DNA sufficiently resembles the histidase polypeptide to co-assemble with normal histidase subunits resulting in an inactive histidase multimer. The high copy number of the plasmid would tend to accentuate this effect. If mixing of normal and defective subunits is in fact the explanation for the trans-dominant efect of pCB102 on chromosomal histidase expression (Table 3), then although the pCB102 deletion enters the hut $H$ gene from the right, it probably leaves a substantial portion of the hutH gene intact. Therefore, hut $H$ probably extends only a short distance to the right of the BamHI site at map position 5.45.

The trans-dominant, histidase-negative phenotype exhibited by pCB102 would explain the inability of pCB102 to complement any of the hut mutants for growth on histidine since little or no active histidase would be produced in such strains. Since histidase activity is not required for metabolizing urocanate, the complementation pattern for growth on urocanate is that which would be expected of a plasmid carrying and expressing hutI, hutG, and hutU. This interference of pCB102 with normal histidase expression also explains the failure of histidine to act as inducer in strain KB897 (Table 3). Urocanase, the enzyme which degrades the inducer, is expressed both from the chromosome and from the plasmid, whereas histidase, the enzyme which synthesizes inducer from histidine, is very poorly expressed so inducer degradation exceeds synthesis. The failure of pCB106, which expresses hutU and hutH, (Table 3) to complement a hutU or hutH mutation can also be explained on physiological grounds. The high copy number of the hutUH operon leads to the histidine-dependent (or urocanate-dependent) production of the toxic intermediate imidazolone propionate (IP). If IP is not further metabolized in hutI strains or is metabolized slowly by a single-copy chromosomal gene, IP accumulates and kills the cell. Thus, while pCB106 carries the information to correct the hut $U$ and $h u t H$ mutations by recombination, growth on histidine or urocanate as sole source of carbon and/or nitrogen is suicidal (Fig. 1).

A map showing the physical locations of the hut genes is shown in Table 2. About $1 \mathrm{~Kb}$ has been allowed for the four structural genes and a little over $0.5 \mathrm{~Kb}$ for the hutC 
gene. This is consistent with the size of the products of the hutG, $\mathrm{U}$ and $\mathrm{H}$ genes from other organisms (Hagen et al. 1974; Magasanik et al. 1971). Our K. aerogenes map is similar to the map of hut from $S$. typhimurium. Blumenberg and Magasanik (1981) found that hut C, P, U and $\mathrm{H}$ end before $3.15,3.7,4.85$ and 6.75 respectively. By comparing the $K$. aerogenes and $S$. typhimurium hut restriction maps, the region of low homology between the two hut operons identified by heteroduplex analysis (Blumenberg and Magasanik 1979) contains the hutC region and not hut $P$ as previously reported.

The placement of the hut genes with respect to the restriction sites which have been mapped on the cloned hut DNA (Boylan et al. 1983) facilitates the studies of in vitro transcription from hutP now being pursued by our laboratory (Nieuwkoop, Boylan, and Bender, manuscript in preparation). We can now locate hutP at map position 3.5. Plasmid pCB111, which contains hut DNA only from the 3.35 4.0 region, carries hutP and would be an excellent choice for further molecular characterization of the regulation of hut $U H$ transcription.

Acknowledgements. We thank S.L. Allen and M.I. Lomax for reading the manuscript, R. Goldberg for providing needed strains, L.J. Eades for expert technical assistance, and A.J. Nieuwkoop and L.J. Eades for helpful discussion. This work was supported by research grants from the NIH, PHS (AI-15822 and GM-27111) and by a Junior Faculty Research Award (JFRA-3) to RAB and a postdoctoral fellowship (PF-1739) to $\mathrm{SAB}$ from the American Cancer Society.

\section{References}

Adams J, Kinney T, Thompson S, Rubin L, Helling RB (1979) Frequency dependent selection for plasmid-containing cells of Escherichia coli. Genetics 91:627-637

Bender RA, Janssen KA, Resnick AD, Blumenberg M, Foor F, Magasanik B (1977) Biochemical parameters of glutamine synthetase from Klebsiella aerogenes. J Bacteriol 129:1001-1009

Boylan SA, Eades LJ, Janssen KA, Lomax MI, Bender RA (1984) A restriction enzyme cleavage map of the histidine utilization (hut) genes of Klebsiella aerogenes and deletions lacking regions of hut DNA. Mol Gen Genet 193:92-98
Blumenberg M, Magasanik B (1981) Physical maps of Klebsiella aerogenes and Salmonella typhimurium hut genes. J Bacteriol $145: 664-667$

Brill WJ, Magasanik B (1969) Genetic and metabolic control of histidase and urocanase in Salmonella typhimurium strain 15-59. J Biol Chem 244:5392-5402

Goldberg RB, Bender RA, Streicher SL (1974) Direct selection for P1-sensitive mutants of enteric bacteria. J Bacteriol $118: 810-814$

Goldberg RB, Hanau R (1980) Regulation of Klebsiella pneumoniae hut operons by oxygen. J Bacteriol 141:745-750

Goldberg RB, Magasanik B (1975) Gene order of the histidine utilization (hut) operons in Klebsiella aerogenes. J Bacteriol 122:1025-1031

Hagen DC, Lipton PJ, Magasanik B (1974) Isolation of a transdominant histidase-negative mutant of Salmonella typhimurium. J Bacteriol 120:906-916

Lederberg EM, Cohen SN (1974) Transformation of Salmonella typhimurium by plasmid deoxyribonucleic acid. J Bacteriol 119:1072-1074

Lowry OH, Rosenbrough NJ, Farr AL, Randall RJ (1951) Protein measurement with the Folin phenol reagent. J Biol Chem $193: 265-275$

Magasanik B (1978) Regulation in the hut system. In Miller JH, Reznikoff WS (ed), The Operon, Cold Spring Harbor Laboratory, New York pp 373-387

Magasanik B, Kaminskas E, Kimhi Y (1971) Histidine degradation (Bacillus subtilis). Methods Enzymol 17B:45-

Neidhardt FC, Magasanik B (1957) Reversal of the glucose inhibition of histidase biosynthesis in Aerobacter aerogenes. J Bacteriol 73:253-259

Prival MJ, Magasanik B (1971) Resistance to catabolite repression of histidase and proline oxidase during nitrogen-limited growth of Klebsiella aerogenes. J Biol Chem 246:6288-6296

Schlesinger S, Magasanik B (1965) Imidazolepropionate a nonmetabolizable inducer for the histidine-degrading enzymes in Aerobacter aerogenes. J Biol Chem 240:4325-4330

Schlesinger S, Scotto P, Magasanik B (1965) Exogenous and endogenous induction of the histidine-degrading enzymes in Aerobacter aerogenes. J Biol Chem 240:4331-4337

Communicated by G. O'Donovan

Received June 25, 1983 